\title{
Synaptic Mechanism for the Sustained Activation of Oculomotor Integrator Circuits in the Rat Prepositus Hypoglossi Nucleus: Contribution of $\mathrm{Ca}^{2+}$-Permeable AMPA Receptors
}

\author{
Yasuhiko Saito $^{1}$ and Yuchio Yanagawa ${ }^{1,2}$ \\ ${ }^{1}$ Department of Genetic and Behavioral Neuroscience, Gunma University Graduate School of Medicine, Gunma 371-8511, Japan, and ${ }^{2}$ Japan Science and \\ Technology Agency, Core Research for Evolutional Science and Technology, Tokyo 102-0075, Japan
}

\begin{abstract}
Sustained neural activity is involved in several brain functions. Although recurrent/feedback excitatory networks are proposed as a neural mechanism for this sustained activity, the synaptic mechanisms have not been fully clarified. To address this issue, we investigated the excitatory synaptic responses of neurons in the prepositus hypoglossi nucleus (PHN), a brainstem structure involved as an oculomotor neural integrator, using whole-cell voltage-clamp recordings in rat slice preparations. Under a blockade of inhibitory synaptic transmissions, the application of "burst stimulation" (100 Hz, 20 pulses) to a brainstem area projecting to the PHN induced an increase in the frequency of EPSCs in PHN neurons that lasted for several seconds. Sustained EPSC responses were observed even when the burst stimulation was applied in the vicinity of a recorded neuron within the PHN that was isolated from the slices. Pharmacologically, the sustained EPSC responses were reduced by 1-naphthyl acetyl spermine $(50 \mu \mathrm{M})$, a blocker of $\mathrm{Ca}^{2+}$-permeable AMPA (CP-AMPA) receptors. Analysis of the current-voltage $(I-V)$ relationship of the current responses to iontophoretic application of kainate revealed that more than one-half of PHN neurons exhibited an inwardly rectifying $I-V$ relationship. Furthermore, PHN neurons exhibiting inwardly rectifying current responses showed higher $\mathrm{Ca}^{2+}$ permeability. The sustained EPSC responses were also reduced by flufenamic acid $(200 \mu \mathrm{M})$, a blocker of $\mathrm{Ca}^{2+}$-activated nonselective cation (CAN) channels. These results indicate that the sustained EPSC responses are attributable to the sustained activation of local excitatory networks in the PHN, which arises from the activation of CP-AMPA receptors and CAN channels in PHN neurons.
\end{abstract}

\section{Introduction}

Several lines of evidence indicate that sustained activities of neurons are involved in the short-term storage of information, which is widely used for sensory, motor, and cognitive brain functions (Goldman-Rakic, 1995; Kiehn and Eken, 1998; Wang, 2001; Major and Tank, 2004). Sustained activities are usually elicited by a brief sensory or motor command. An input-output relationship, such as sustained outputs in response to brief inputs, is well recognized in the oculomotor system. Motoneurons projecting to the extraocular muscles carry sustained signals proportional to eye position for gaze holdings and to velocity signals for eye movements (Fuchs and Luschei, 1970; Robinson, 1970; Schiller, 1970). However, a specific class of premotor brainstem neurons projecting to extraocular motoneurons carry transient burst sig-

\footnotetext{
Received June 3, 2010; revised Sept. 15, 2010; accepted Sept. 21, 2010.

This work was supported by Grant-in-Aid for Scientific Research on Priority Areas from Ministry of Education, Culture, Sports, Science, and Technology and Grant-in-Aid for Scientific Research from Japan Society for the Promotion of Science. We thank Seiji Ozawa for helpful comments on this manuscript, Masato Shino for partial participation in the experiments, and Masae lino and the members of our laboratory for technical assistance and comments.

Correspondence should be addressed to Dr. Yasuhiko Saito, Department of Genetic and Behavioral Neuroscience, Gunma University Graduate School of Medicine, 3-39-22 Showa-machi, Maebashi, Gunma 371-8511, Japan. E-mail: syasu@med.gunma-u.ac.jp.

DOI:10.1523/JNEUROSCI.2814-10.2010

Copyright $\odot 2010$ the authors $\quad 0270-6474 / 10 / 3015735-12 \$ 15.00 / 0$
}

nals proportional to eye velocity (Keller, 1974; Igusa et al., 1980; Van Gisbergen et al., 1981; Strassman et al., 1986). Therefore, while transmitting signals from premotor neurons to motoneurons, velocity signals must be converted into position signals. Since this process corresponds to a mathematical time integration, the brain area involved in this function is known as a neural integrator (Robinson, 1975, 1989; Fukushima et al., 1992; Fukushima and Kaneko, 1995; Moschovakis, 1997).

The prepositus hypoglossi nucleus (PHN), located in the pontomedullary region, receives projections from the premotor brainstem areas and projects to the extraocular motor nuclei (McCrea and Baker, 1985b; McCrea, 1988; McCrea and Horn, 2006). Electrical or chemical lesions of the PHN result in a failure of horizontal gaze holding in eccentric positions (Cheron et al., 1986a,b; Cannon and Robinson, 1987; Cheron and Godaux, 1987). Furthermore, neurons exhibiting firing responses related not only to eye velocity but also to eye position exist in the PHN (Lopez-Barneo et al., 1982; Delgado-García et al., 1989; Escudero et al., 1992; McFarland and Fuchs, 1992). These findings strongly indicate that the PHN plays a major role as the neural integrator for horizontal gaze holding.

Several hypotheses have been proposed regarding the neural mechanisms of signal transformation in the neural integrator. 
According to accepted models, sustained activities can be produced by neural network mechanisms, such as positive-feedback excitation through a mutual inhibition between the bilateral integrator regions and/or a recurrent excitation in the integrator (Cannon et al., 1983; Galiana and Outerbridge, 1984; Cannon and Robinson, 1985; Arnold and Robinson, 1997; Draye et al., 1997; Seung et al., 2000). Indeed, local and commissural networks of the PHN have been suggested (McCrea and Baker, 1985a; McCrea and Horn, 2006), and the blockade of excitatory or inhibitory synaptic transmissions in the PHN induces an impairment in gaze holding (Cheron et al., 1992; Mettens et al., 1994a,b; Arnold et al., 1999). Furthermore, studies on goldfish area I, corresponding to the mammalian PHN, suggest synaptic feedback mechanisms of the sustained activities (Aksay et al., 2001, 2003). The experimental findings also support neural network mechanisms of the neural integrator; however, synaptic mechanisms for sustained activities in the PHN have not been fully clarified. In the present study, we investigated synaptic transmissions performed in PHN excitatory networks using whole-cell voltage-clamp recordings in rat brainstem slices.

\section{Materials and Methods}

All experimental procedures were approved by the Animal Care and Experimentation Committee of Gunma University (approval number 07-028, 10-003). Every effort was made to minimize the number of animals used and their suffering.

Slice preparation. The brainstem slices were prepared from Wistar rats (16-20 postnatal days old) under deep anesthesia with isoflurane. Parasagittal (400 $\mu \mathrm{m}$ thick) or frontal slices (300 $\mu \mathrm{m}$ thick) were cut using a Microslicer (Pro7; Dosaka) in an ice-cold sucrose solution and were incubated in a normal extracellular solution at room temperature for $>1$ $\mathrm{h}$ before recording. Two parasagittal slices that were closest to the midline and included the PHN and pontine reticular formation were used for experiments. Of the four to five frontal slices, including the PHN, that were usually obtained from each animal, three successive slices from the rostral side were used for experiments.

Whole-cell patch-clamp recordings. The slice was placed in a conventional submersion chamber on an upright microscope and continuously superfused with a normal extracellular solution at a rate of $5 \mathrm{ml} / \mathrm{min}$. The bath temperature was kept at $30-32^{\circ} \mathrm{C}$ with an in-line heater $(\mathrm{SH}-27 \mathrm{~A}$; Warner Instruments). Patch pipettes were prepared from borosilicate glass capillaries and filled with an internal solution containing the following (in mM): 145 Cs-gluconate, 5 CsCl, 0.2 EGTA, 2 Mg-ATP, 0.3 Na-GTP, 10 HEPES, 0.1 spermine, and 5 QX-314 (lidocaine $N$-ethyl bromide), $\mathrm{pH}$ 7.3. The osmolarity of the internal solution was $280-290$ $\mathrm{mOsm} / \mathrm{L}$, and the resistance of electrodes was 4-7 $\mathrm{M} \Omega$ in the bath solution. Whole-cell voltage-clamp recordings were performed using an EPC-8 patch-clamp amplifier (HEKA). PHN neurons that were located near the center of the PHN in each slice were selected for recordings. Membrane potential was usually held at $-75 \mathrm{mV}$ during recordings of EPSC responses. Current signals were low-pass filtered at $3 \mathrm{kHz}$ and digitized at $5-10 \mathrm{kHz}$. Neurons with a membrane potential more negative than $-50 \mathrm{mV}$ immediately after patch membrane rupture and exhibiting spontaneous currents before stimulation were used for additional analyses. When current responses to electrical stimulation were recorded, five current traces were usually recorded in each solution containing the antagonists or blockers used in this study and in the control solution.

Electrical stimulation. A concentric bipolar electrode (Clarke Electromedical Instruments) was placed at the dorsal part of the nucleus pontis caudalis $(\mathrm{Pc})$ (see Fig. 1 A1) with reference to the brain atlas (Paxinos and Watson, 2007). Electrical stimulation of 20 cathodal square-wave pulses $(80-200 \mu \mathrm{A}, 100 \mu \mathrm{s}$ in duration) was applied at a frequency of $100 \mathrm{~Hz}$ (burst stimulation) to the Pc at an interval of $20 \mathrm{~s}$. When burst stimulation was applied in the vicinity of a recorded PHN neuron, a glass micropipette that was filled with the control solution was used for stimulation. To determine the stimulation site, we scanned 8-10 differ- ent sites around a recorded neuron with the application of burst stimulation $(10-25 \mu \mathrm{A})$ to each site. A site where the current responses of the neuron appeared to be the largest was determined as an appropriate stimulation site. After recordings, we measured the distance between the tip of the stimulus electrode and the soma of the recorded neurons. The distance was 20-80 $\mu \mathrm{m}$ (see Fig. 1D1).

Iontophoretic application of glutamate agonists. To characterize current responses mediated by AMPA receptors, we recorded the current responses of PHN neurons to an iontophoretic application of kainate, which is a non-desensitizing agonist of AMPA receptors (Kiskin et al., 1986; Patneau and Mayer, 1991). To minimize the number of animals used, the frontal slice was further separated into right and left halves at the midline for use in each experiment. Kainate $(20 \mathrm{~mm})$ filled in a sharp glass micropipette was applied to the soma of a recorded neuron by iontophoresis using a 3-8 ms current pulse of $1000 \mathrm{pA}$ in intensity. We first determined the reversal potential at which the application of kainate induced no current deflection from the baseline. Thereafter, the recordings were performed by changing the holding potentials from -100 to $+60 \mathrm{mV}$ in $20 \mathrm{mV}$ steps. When kainate and NMDA responses were recorded from a single neuron, kainate and NMDA (100 mM) were filled in different micropipettes and applied at a membrane potential of -70 and $+40 \mathrm{mV}$ with the same current pulse condition, respectively. The tips of micropipettes of kainate and NMDA were placed near the soma of the recorded neuron. The location of the tip of NMDA micropipette was same as that of the tip of kainate micropipette.

Drugs and extracellular solution. Strychnine hydrochloride, 1-naphthyl acetyl spermine (NAS), and flufenamic acid (FFA) were purchased from Sigma-Aldrich; D-(-)-2-amino-5-phosphonopentanoic acid (APV), 2,3dioxo-6-nitro-1,2,3,4-tetrahydrobenzo[f] quinoxaline-7-sulfonamide disodium salt (NBQX), kainic acid, and $(s)$ - $\alpha$-methyl-4-carboxyphenylglycine (MCPG) were purchased from Tocris Bioscience; and picrotoxin and tetrodotoxin were purchased from Wako Pure Chemicals. Picrotoxin and MCPG were dissolved directly in the solutions. All drugs, with the exception of FFA, were dissolved in water (1000 times the final concentration) and stored as stock solutions at $-20^{\circ} \mathrm{C}$ before being diluted in the oxygenated solutions. FFA stock was prepared in DMSO (2000 times the final concentration).

Sucrose and normal extracellular solutions contained the following (in mM): 234 sucrose, $2.5 \mathrm{KCl}, 1.25 \mathrm{NaH}_{2} \mathrm{PO}_{4}, 10 \mathrm{MgSO}_{4}, 0.5 \mathrm{CaCl}_{2}, 26$ $\mathrm{NaHCO}_{3}$, and 11 glucose, and $125 \mathrm{NaCl}, 2.5 \mathrm{KCl}, 2 \mathrm{CaCl}_{2}, 1 \mathrm{MgCl}_{2}, 1.25$ $\mathrm{NaH}_{2} \mathrm{PO}_{4}, 26 \mathrm{NaHCO}_{3}$, and 25 glucose, respectively. Both solutions were bubbled with $95 \% \mathrm{O}_{2}$ and $5 \% \mathrm{CO}_{2}, \mathrm{pH}$ 7.4. When a Na${ }^{+}$-free, high$\mathrm{Ca}^{2+}$ solution containing the following (in mM): $125 \mathrm{NMG}$ ( $\mathrm{N}$-methylD-glucamine), $2.5 \mathrm{KCl}, 20 \mathrm{CaCl}_{2}, 1 \mathrm{MgCl}_{2}, 5 \mathrm{HEPES}$, and 10 glucose was used, the control solution contained the following (in $\mathrm{mM}$ ): $145 \mathrm{NaCl}, 2.5$ $\mathrm{KCl}, 2 \mathrm{CaCl}_{2}, 1 \mathrm{MgCl}_{2}, 5 \mathrm{HEPES}$, and 10 glucose. The $\mathrm{pH}$ of the control and the $\mathrm{Na}^{+}$-free, high-Ca ${ }^{2+}$ solutions was adjusted to 7.4 using $\mathrm{NaOH}$ and $\mathrm{HCl}$, respectively, and both were bubbled with $100 \% \mathrm{O}_{2}$. All current recordings were performed in the solutions described above, to which picrotoxin (antagonist of $\mathrm{GABA}_{\mathrm{A}}$ receptors; final concentration, $100 \mu \mathrm{M}$ ) and strychnine (antagonist of glycine receptors; final concentration, 20 $\mu \mathrm{M}$ ) were added. When NMDA responses were recorded, glycine (final concentration, $10 \mu \mathrm{M}$ ), a coagonist of NMDA receptors, was added to the solution to keep the concentration of glycine constant.

Data analysis. The EPSC was determined when the peak of the inward current was more than three times the SD of the baseline noise before burst stimulation. To detect EPSCs after burst stimulation, an inward deflection of the baseline, presumably because of the summation of highfrequency inward currents that occurred immediately after burst stimulation and returned to the origin by $\sim 300 \mathrm{~ms}$ (see Fig. 1), was removed by the subtraction of the trace filtered up to $10 \mathrm{~Hz}$ from the original trace. To characterize current responses to burst stimulation, we analyzed (1) the increase in the frequency of EPSCs and the total currents after burst stimulation and (2) the duration of the increased EPSC frequency. The EPSC frequencies before and after burst stimulation were analyzed from recordings of $2 \mathrm{~s}$ before and $1 \mathrm{~s}$ after burst stimulation, respectively. The total currents before and after burst stimulation were estimated as the charge transfers that were the areas of currents measured for $300 \mathrm{~ms}$ before and after burst stimulation, respectively. To estimate the duration of the increased EPSC frequency, we made a histogram showing the 
A 1
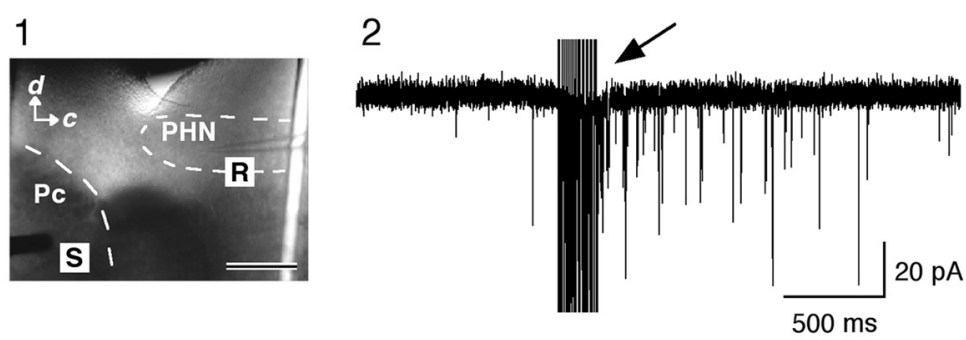

B
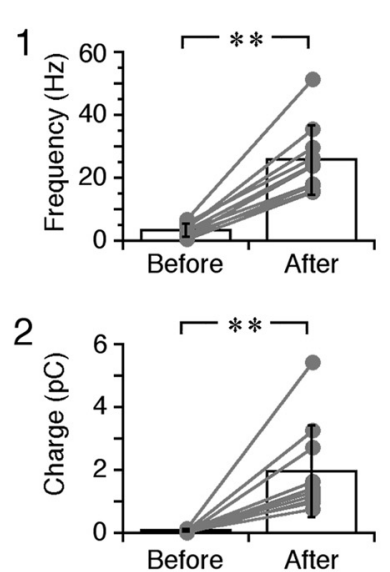

C

1

2

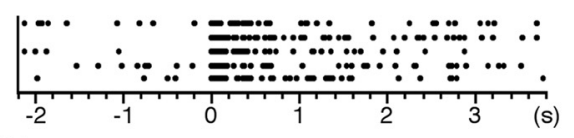

$2(\mathrm{~Hz})$

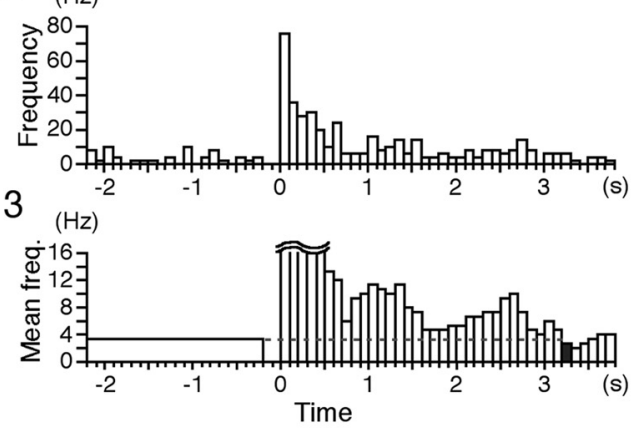

E

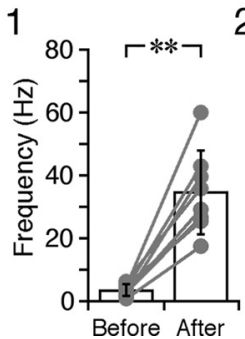

2

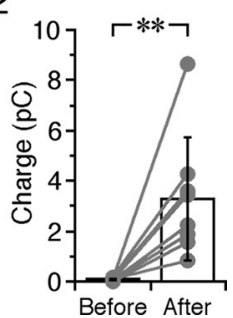

Figure 1. The frequency of inward currents was increased by burst stimulation. A1, Photomicrograph of a parasagittal slice of the brainstem. $R$ and $S$ indicate the location of a recording and a stimulating electrode, respectively. The dashed lines show rough boundaries of the PHN and Pc. d, Dorsal; c, caudal. Scale bar, $400 \mu \mathrm{m}$. A2, Current response of a PHN neuron to high-frequency burst stimulation (arrow) that was applied to the Pc. $\boldsymbol{B}$, Comparisons of the frequency (B1) and charge transfer $(\boldsymbol{B} 2)$ of inward currents before and after burst stimulation. The gray plots connected by a line were obtained from individual neurons $(n=10)$. C1, Raster plot showing the peak time of each EPSC. The termination time of burst stimulation is shown as 0 . Each row in the raster represents one recording. C2, A histogram showing the frequency of inward currents against time. Bin width of the histograms is $100 \mathrm{~ms}$. C3, A histogram showing the averaged frequency of inward currents against time. The bin before burst stimulation was made from the average of the frequency over $2 \mathrm{~s}$, whereas each bin after burst stimulation was made from the average of the three bins in the frequency histogram of $\mathbf{C}$. The filled bin in $\mathbf{C}$ indicates the averaged frequency that became equal or smaller than the averaged frequency before burst stimulation (broken line). The duration of the increased frequency of inward currents of this neuron was estimated as 3.2 s. D1, Photomicrograph of the PHN in a frontal slice and the location of a recording (R) and a stimulating electrode (S). Scale bar, $20 \mu \mathrm{m}$. D2, Current response of a PHN neuron to burst stimulation (arrow) that was applied in the vicinity of the recorded neuron. $\boldsymbol{E}$, Comparisons of the frequency $(\boldsymbol{E} 1)$ and charge transfer $(\boldsymbol{E} 2)$ of inward currents before and after burst stimulation. The gray plots connected by a line were obtained from individual neurons $(n=8)$. The asterisks indicate significant differences between groups $\left({ }^{* *} p<0.01\right)$. Error bars represent SD.

EPSC frequency against time (see Fig. 1C2). Using the histogram, the duration was defined as the period from the time when burst stimulation was terminated to the time when the averaged value of three adjacent bins (corresponding to $300 \mathrm{~ms}$ ) became equal or smaller than the average baseline EPSC frequency before burst stimulation, as illustrated in Figure 1C3. The amplitude of EPSCs before and after burst stimulation was determined as the averaged amplitude of EPSCs for $2 \mathrm{~s}$ before and $1 \mathrm{~s}$ after burst stimulation. To characterize the current responses mediated by AMPA receptors, we analyzed the rectification index (RI) (Ozawa et al., 1991). The RI was calculated using the following formula: RI $=\left(I_{+40}\right)$
$+40) /\left(I_{-60} /-60\right)$, where $I_{+40}$ and $I_{-60}$ represent the amplitude of kainate-induced currents at a membrane potential of +40 and $-60 \mathrm{mV}$ from the reversal potential, respectively. The rectification properties are approximately separated by the RI value of 1 ; RI $<1$ and RI $\geq 1$ indicate current responses with inwardly and outwardly rectifying properties, respectively. All values are shown as the mean $\pm \mathrm{SD}$, and error bars in the figures also represent SD. Statistical significance was analyzed using Student's $t$ test (paired or unpaired data) or one-way repeatedmeasures ANOVA followed by post hoc Scheffé's test using StatView or JMP software (Hulinks). Statistical significance was considered at the $p<$ 0.05 level for all statistical tests.

\section{Results}

\section{Current responses of PHN neurons to burst stimulation}

One of the premotor brain areas projecting to the $\mathrm{PHN}$ is the paramedian pontine reticular formation (PPRF), which includes the nuclei pontis caudalis $(\mathrm{Pc})$ and oralis (McCrea, 1988; Iwasaki et al., 1999). Indeed, Navarro-López et al. $(2004,2005)$ succeeded in obtaining excitatory synaptic responses in PHN neurons to stimulation of the PPRF in rat brainstem parasagittal slices. Therefore, we investigated the current responses of PHN neurons to PPRF stimulation in parasagittal slices (Fig. 1A1). To clarify excitatory responses, we performed recordings under the blockade of inhibitory synaptic transmissions using the application of $100 \mu \mathrm{M}$ picrotoxin and $20 \mu \mathrm{M}$ strychnine. When burst stimulation was applied to the Pc, the frequency of inward currents increased dramatically (Fig. 1 A2). Comparisons of the frequency of inward currents (Fig. 1B1) and charge transfer (Fig. 1B2) between before and after burst stimulation showed a dramatic increase in the inward currents after burst stimulation $(p<0.01 ; n=10)$. The amplitude of individual inward currents before and after burst stimulation were not statistically different (before, $14.5 \pm 3.9 \mathrm{pA}$; after, $16.7 \pm 6.2 \mathrm{pA} ; p=0.052$ ). The raster plots and the histogram of the frequency of inward currents showed that the high frequency of inward currents immediately after burst stimulation gradually decreased over time (Fig. 1C1,C2). Analysis of the duration of the increased frequency of inward currents based on the averaged frequency histogram (Fig. 1C3) (see Materials and Methods) revealed that the duration was usually longer than $1 \mathrm{~s}(2.4 \pm 1.2 \mathrm{~s} ; n=10)$, which far outlasted burst stimulation. A sustained increase in the frequency of inward currents was also observed when burst stimulation was applied in the vicinity of a recorded PHN neuron in frontal slices (Fig. 1D, $50 \mu \mathrm{m}$ from the soma in this recording). The frequency and charge transfer after burst stimulation were significantly 
A

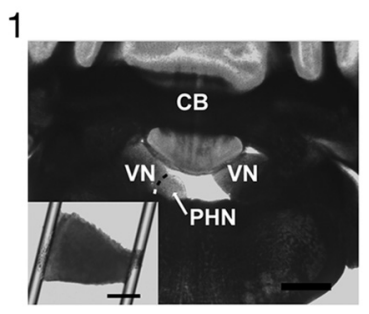

B

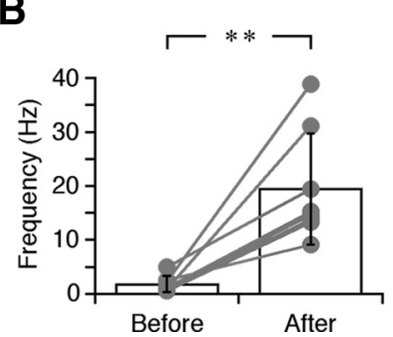

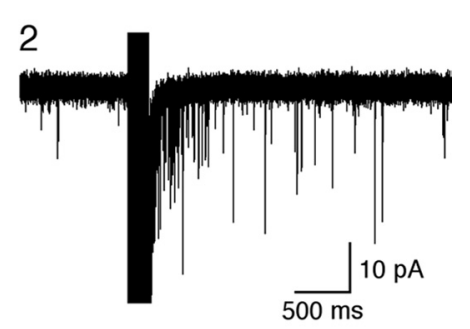

C

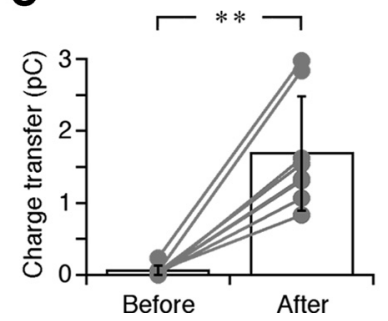

Figure 2. Sustained responses were induced in the PHN local network. A1, Photomicrograph of a frontal slice after separation of the right PHN. VN, Vestibular nuclei; CB, cerebellar cortex. Scale bar, $1 \mathrm{~mm}$. Inset, Photomicrograph of the PHN separated from the slice. Scale bar, $0.5 \mathrm{~mm}$. $\boldsymbol{A 2}$, Current responses of a neuron in the isolated PHN to local burst stimulation. $\boldsymbol{B}, \boldsymbol{C}$, Comparisons of the EPSC frequency $(\boldsymbol{B})$ and charge transfer $(\boldsymbol{C})$ before and after burst stimulation. The gray plots connected by a line were obtained from individual neurons $(n=8)$. All traces are presented as the superimposition of three traces. The asterisks indicate significant differences between groups $\left({ }^{* *} p<0.01\right)$. Error bars represent SD.

larger than those before burst stimulation $(p<0.01 ; n=8)$ (Fig. $1 E)$. The mean duration of the increased frequency was $2.1 \pm$ $0.9 \mathrm{~s}(n=8)$. The current responses appeared to be dependent on the stimulus conditions. Both the frequency and charge transfer were increased when the number and frequency of stimulus pulses were increased (supplemental Fig. S1, available at www. jneurosci.org as supplemental material). Since more slices suitable for recordings can be obtained from frontal slices than parasagittal slices, frontal slices were used in subsequent experiments.

To investigate whether the sustained current responses were generated within the PHN, we separated the PHN from the brainstem slice by cutting, as shown in Figure $2 A 1$, and recorded inward currents from neurons in the isolated PHN. When burst stimulation was applied in the vicinity of the recorded neurons, an increase in the frequency of inward currents was observed (Fig. 2A2, $36 \mu \mathrm{m}$ from the soma in this recording). Both the frequency and the charge transfer after burst stimulation were significantly larger than those before burst stimulation $(p<0.01$; $n=8$ ) (Fig. $2 B, C$ ). The mean duration of increased frequency was $1.7 \pm 0.3 \mathrm{~s}(n=8)$, which was comparable with the results obtained in the frontal $(p=0.32)$ and sagittal slices $(p=0.13)$. This result suggests that the excitatory networks necessary to produce the sustained current responses observed in this study exist within the PHN.

\section{Sustained responses are mediated by ionotropic glutamate receptors}

When antagonists of AMPA-type glutamate receptors (NBQX; $20 \mu \mathrm{M}$ ) and NMDA-type glutamate receptors (APV; $50 \mu \mathrm{M}$ ) were applied, inward currents were abolished completely (Fig. $3 A$ ). This abolishment of current was observed in all recorded PHN neurons $(n=10)$. This finding confirms that inward currents are indeed EPSCs and are attributed to the activation of glutamate

receptors. In addition to the ionotropic glutamate receptors, several kinds of subunit of metabotropic glutamate receptors (mGluRs) are expressed in PHN neurons and in neurons in the premotor brainstem nuclei (Shigemoto et al., 1992; Ohishi et al., 1993a,b). To investigate whether the activation of mGluRs participates in the sustained EPSC responses to burst stimulation, we recorded EPSCs in the presence of a nonselective antagonist of group I/II mGluRs [(s)-MCPG; 1 mM] (Anwyl, 1999; Hölscher et al., 1999). The duration, EPSC frequency, and charge transfer were not significantly different between before and after applications of $(s)$-MCPG (duration, $p=0.81$; frequency, $p=0.31$; charge, $p=0.58 ; n=8$ ) (Fig. $3 B$ ). This indicates that the sustained EPSC responses are mediated by ionotropic glutamate receptors.

\section{Pharmacological analysis of glutamatergic synaptic transmissions}

As the results described above indicated that activation of ionotropic glutamate receptors is essential for the sustained EPSC responses, we further investigated synaptic mechanisms that involve ionotropic glutamate receptors. It has been reported that the synaptic transmissions via NMDA receptors may play important roles in gaze holding (Cheron et al., 1992; Mettens et al., 1994a). Therefore, we investigated the contribution of NMDA receptors to the sustained EPSC responses. The application of 50 $\mu \mathrm{M}$ APV appeared to reduce EPSCs (Fig. 4A1,A2). In fact, the amplitude of EPSCs in the presence of APV $(18.3 \pm 5.2 \mathrm{pA})$ was significantly smaller than the amplitudes in the absence of APV $(21.4 \pm 6.8 \mathrm{pA} ; n=10$ cells; $p<0.05)$. However, a higher EPSC frequency than before burst stimulation lasted for several seconds after burst stimulation. This was clearly shown by a comparison of the histograms in the absence and presence of APV (Fig. $4 B 1, B 2)$. In the presence of APV, the appearance of a gradual decrease in EPSC frequency was similar to that in the control. The duration of the increased EPSC frequency $(1.7 \pm 0.6 \mathrm{~s})$ as well as the EPSC frequency $(19.7 \pm 7.8 \mathrm{~Hz})$ and charge transfer $(1.1 \pm$ $0.7 \mathrm{pC}$ ) after burst stimulation in the presence of APV were not significantly different from those in the control (duration: $2.0 \pm$ $0.6 \mathrm{~s}, p=0.58$; frequency: $21.9 \pm 7.9 \mathrm{~Hz}, p=0.77$; charge: $1.7 \pm$ $0.8 \mathrm{pC}, p=0.22 ; n=10$ ) (Fig. $4 C$ ). This suggests that the activation of NMDA receptors is not involved in the sustained EPSC responses observed in this study.

As described above, the application of NBQX in addition to APV completely abolished EPSCs (Fig. $2 A$ ). In terms of $\mathrm{Ca}^{2+}$ permeability, AMPA-type glutamate receptors are classified into two canonical types: one exhibits an outwardly rectifying current-voltage $(I-V)$ relationship and little $\mathrm{Ca}^{2+}$ permeability $\left[\mathrm{Ca}^{2+}\right.$-impermeable AMPA (CI-AMPA) receptor], and the other exhibits an inwardly rectifying $I-V$ relationship and high $\mathrm{Ca}^{2+}$ permeability $\left[\mathrm{Ca}^{2+}\right.$-permeable AMPA (CP-AMPA) receptor] (Iino et al., 1990; Hume et al., 1991; Burnashev et al., 1992; Ozawa and Iino, 1993) (for review, see Jonas and Burnashev, 1995; Ozawa et al., 1998). Although both synaptic currents through CI-AMPA and CP-AMPA receptors are blocked by NBQX, the latter is specifically blocked by the toxins related to the joro spider toxin (JSTX) (Kawai et al., 1982; Blaschke et al., 1993). Therefore, we investigated the effect of NAS (50 $\mu \mathrm{M})$ (Asami et al., 1989; Koike et al., 1997), a synthetic analog of JSTX, on EPSC responses. NAS, at a concentration of $50 \mu \mathrm{M}$, preferentially blocked the current responses exhibiting an inwardly rectifying $I-V$ relationship (supplemental Fig. S2, available at www.jneurosci.org as supplemental material). The application of NAS in addition to APV markedly decreased the EPSC frequency after burst stimu- 
A

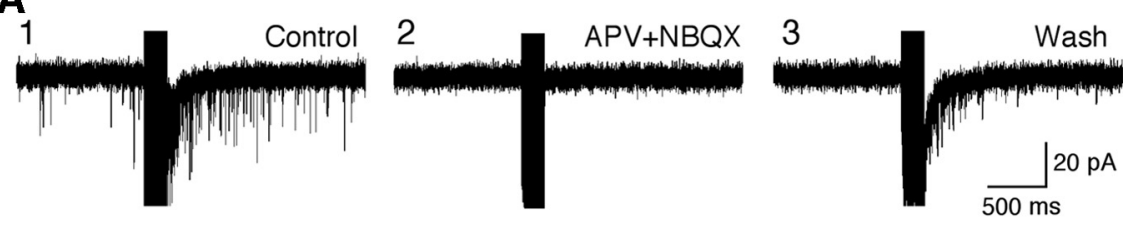

B
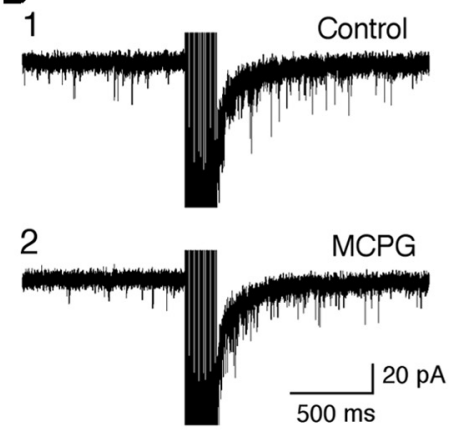

3

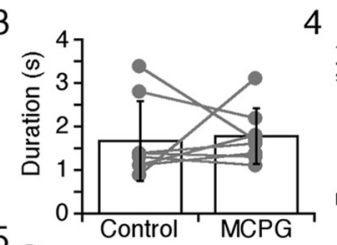

4
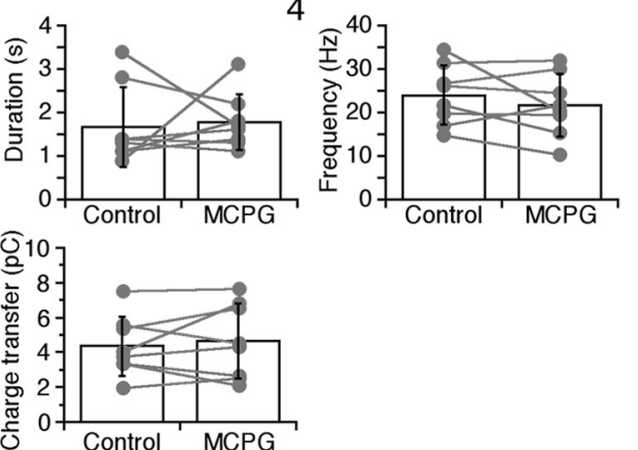

Figure 3. Current responses were mediated by ionotropic glutamatergic synaptic transmissions. $A$, Current responses of a PHN neuron to local burst stimulation in control solution (A1), in the solution containing $50 \mu \mathrm{M} \mathrm{APV}$ and $20 \mu \mathrm{M} \mathrm{NBQX}(\boldsymbol{A 2})$, and after the washing out of APV and NBQX (A3). Inward currents were abolished almost completely by the application of APV and NBQX and partially recovered after the washing out of the drugs $(n=10)$, indicating that the currents were indeed glutamatergic EPSCs. $\boldsymbol{B}$, EPSC responses of a PHN neuron to local burst stimulation in control solution (B1) and in a solution containing $1 \mathrm{mM} \mathrm{MCPG} \mathrm{(B2).}$ Comparisons of the duration of increased EPSC frequency (B3), EPSC frequency (B4), and charge transfer (B5) between the control solution and a solution containing MCPG. The gray plots connected by a line were obtained from individual neurons $(n=8)$. All traces are presented as the superimposition of three traces. Error bars represent SD.

lation (Fig. 4A3,B3). Furthermore, a comparison of the expanded histograms (Fig. $4 B$, insets) clarified that the EPSC frequency in the presence of APV and NAS decreased rapidly in contrast to those in the control and in the presence of APV alone. The duration $(0.6 \pm 0.3 \mathrm{~s})$ and EPSC frequency $(8.5 \pm 3.5 \mathrm{~Hz})$ in the presence of AVP and NAS were significantly smaller than the duration and frequency observed in the control and in the presence of APV alone $\left(n=10\right.$; duration: $F_{(2,27)}=19.3, p<0.0001$; frequency: $\left.F_{(2,27)}=11.6, p=0.0002\right)$ (Fig. $\left.4 C 1, C 2\right)$. The charge transfer $(0.4 \pm 0.4 \mathrm{pC})$ was significantly smaller than in the control $\left(F_{(2,27)}=8.8 ; p=0.0011\right)$ (Fig. 4C3). However, the baseline EPSC frequency was not significantly different among the control $(2.0 \pm 1.0 \mathrm{~Hz}), \mathrm{APV}$ alone $(2.1 \pm 1.2 \mathrm{~Hz})$, and APV and NAS $(1.7 \pm 1.0 \mathrm{~Hz})$ conditions $\left(F_{(2,27)}=0.47 ; p=0.63\right)$ (Fig. $\left.4 C 4\right)$.

The EPSC responses were reduced when NAS was applied alone (Fig. $4 D)$. The duration $(0.7 \pm 0.4 \mathrm{~s})$, EPSC frequency $(12.4 \pm 6.2 \mathrm{~Hz})$, and charge transfer $(1.0 \pm 0.4 \mathrm{pC})$ were significantly smaller in the presence of NAS than in the control (duration: $2.2 \pm 0.9 \mathrm{~s}, p<0.01$; frequency: $25.4 \pm 10.2 \mathrm{~Hz}, p<0.01$; charge: $2.6 \pm 1.1 \mathrm{pC}, p<0.01 ; n=7$ ) (Fig. 4E1-E3). The baseline EPSC frequency was not different between the control and NAS ( $p=0.61)$ (Fig. 4E4). A similar effect of NAS on EPSC responses was observed using $10 \mu \mathrm{M}$ philanthotoxin $433(\mathrm{PhTx}$ ) (Eldefrawi et al., 1988), which is a different blocker of CP-AMPA receptors and is also used for the blockade of CP-AMPA receptor-mediated currents (Washburn and Dingledine, 1996; Tóth and McBain, 1998; Plant et al., 2006; Satake et al., 2006). The duration, EPSC frequency, and charge transfer in the presence of $\operatorname{PhTx}(1.0 \pm$ $0.2 \mathrm{~s} ; 7.5 \pm 2.0 \mathrm{~Hz} ; 1.2 \pm 0.8 \mathrm{pC} ; n=6)$ were significantly smaller than in controls $(2.4 \pm 0.6 \mathrm{~s}, p<0.01 ; 19.7 \pm 8.4 \mathrm{~Hz}, p<0.01$; $2.6 \pm 1.4 \mathrm{pC}, p<0.05)$.

\section{Expression of $\mathrm{Ca}^{2+}$-permeable AMPA} receptors in PHN neurons

The pharmacological analyses indicated that the activation of CP-AMPA receptors was involved in the sustained EPSC responses. Because the responses occurred even in the isolated PHN, we suspected that there were PHN neurons that expressed CP-AMPA receptors. This was verified by the analyses of the current responses to the iontophoretic application of kainate. Figure $5 \mathrm{~A}$ shows the current responses of two PHN neurons to kainate. The neuron, as shown in Figure 5A1, exhibited the amplitude of current at +40 $\mathrm{mV}$ comparable with that at $-60 \mathrm{mV}$. The RI value of this neuron was $>1$, indicating that the current responses mediated by AMPA receptors exhibited an outwardly rectifying property. However, the other neuron exhibited the amplitude of current at $+40 \mathrm{mV}$ that was much smaller than the current amplitude at $-60 \mathrm{mV}$ $(\mathrm{RI}<1)$ (Fig. 5A2), indicating that its current responses exhibited an inwardly rectifying property. Of $131 \mathrm{PHN}$ neurons recorded, more than one-half (75 of 131) exhibited RI $<1$ (Fig. 5B). Although it is not certain whether the distribution obtained in this study represents the entire distribution of PHN neurons exhibiting different RI values because of the sampling of neurons from restricted regions in the PHN, our data strongly suggest that a substantial number of PHN neurons exhibit AMPA-receptormediated inwardly rectifying current responses.

To clarify whether AMPA receptors exhibiting $\mathrm{RI}<1$ are actually permeable to $\mathrm{Ca}^{2+}$, we examined the reversal potential of the current responses in $\mathrm{a} \mathrm{Na}^{+}$-free, high- $\mathrm{Ca}^{2+}(20 \mathrm{mM})$ solution. Figure 5 , $C$ and $D$, shows examples of current responses of two PHN neurons to kainate. In the neuron exhibiting an outwardly rectifying $I-V$ relationship in the control solution $(\mathrm{RI}=1.46)$ (Fig. $5 \mathrm{Cl}$; $C 3$, open circles), only a slight inward current was observed even at a holding potential of $-100 \mathrm{mV}$ (Fig. 5C2; C3, filled circles), and the reversal potential was approximately $-60 \mathrm{mV}$ in the $\mathrm{Na}^{+}$-free, high- $-\mathrm{Ca}^{2+}$ solution. However, in the neuron exhibiting an inwardly rectifying $I-V$ relationship in the control solution $(\mathrm{RI}=0.69)$ (Fig. $5 D 1 ; D 3$, open circles), the inward currents were clearly observed at holding potentials from -80 to $-20 \mathrm{mV}$ (Fig. $5 D 2 ; D 3$, filled circles), and the reversal potential was approximately $-20 \mathrm{mV}$. Plots of the reversal potentials obtained in the $\mathrm{Na}^{+}$-free, high-Ca ${ }^{2+}$ solution against the $\mathrm{RI}$ values obtained in the control solution revealed a negative correlation (Fig. 5E1). Plots of the relative permeability coefficients of $\mathrm{Ca}^{2+}$ to $\mathrm{Cs}^{+}$, estimated from the reversal potential using the constant-field equation (Iino et al., 1990) against RI, confirmed that $\mathrm{Ca}^{2+}$ permeability was higher in neurons exhibiting $\mathrm{RI}<1$ than those exhibiting $\mathrm{RI} \geq 1$ (Fig. 5E2). These findings indicate that a substantial number of PHN neurons express AMPA receptors with $\mathrm{Ca}^{2+}$ permeability.

All these results strongly suggest that the activation of excitatory networks composed of PHN neurons expressing CP-AMPA receptors contribute to the sustained EPSC responses. Therefore, the question of whether the excitatory networks are composed of only PHN neurons with CP-AMPA receptors is raised. To an- 
swer this question, we investigated the relationship between EPSC responses and RI. In PHN neurons exhibiting sustained EPSC responses $(n=28)$, both types of neurons, exhibiting outwardly and inwardly rectifying responses to kainate, were observed (Fig. 5F, G). The duration of the increased EPSC frequency was not correlated to the RI $(r=0.04 ; p=$ 0.86) (Fig. 5H). The EPSC frequency and charge transfer were not correlated to the RI either (frequency: $r=-0.18, p=0.37$; charge: $r=-0.18, p=0.36)$. These results suggest that PHN neurons without CP-AMPA receptors are also included in the excitatory networks for the sustained EPSC response.

Although our findings suggest that NMDA receptors are not involved in the sustained EPSC response, they likely have a function in the PHN (Navarro-López et al., 2005; Idoux et al., 2006). Wang and colleagues analyzed the biophysical properties of persistent activity using cortical network models and proposed that a larger ratio of synaptic currents mediated by NMDA receptors to AMPA receptors (NMDA/AMPA ratio) is involved in the stabilization of persistent activity (Wang, 1999; Compte et al., 2000; Tegnér et al., 2002). Therefore, we analyzed the current responses mediated not only by AMPA receptors, but also by NMDA receptors induced by the iontophoretic application of kainate and NMDA to the soma. Figure $6 A$ shows examples of the current responses of two PHN neurons exhibiting different RI values to NMDA $(\mathrm{N})$ and kainate $(\mathrm{K})$ application. The NMDA response, relative to the kainate response, was higher in the neuron exhibiting RI $>$ 1 (Fig. 6A1) than in the neuron exhibiting $\mathrm{RI}<1$ (Fig. 6A2). Figure $6 B$ shows the plots of the NMDA/AMPA ratio against the RI of recorded PHN neurons $(n=43)$. The NMDA/AMPA ratio was positively correlated with RI $(r=0.51 ; p<0.01)$, although some neurons exhibiting RI $<1$ had high NMDA/AMPA ratios. Previous studies on cerebral and hippocampal pyramidal neurons and spinal cord neurons have shown that the expression of NMDA receptors is constant or decreases from the soma to the dendrites, but the expression of AMPA receptors in the soma is lower than in the dendrites (Onodera and Takeuchi, 1991; Dodt et al., 1998; Andras-

falvy and Magee, 2001). If the distribution of AMPA and NMDA receptors at the somatic-dendritic membrane in PHN neurons is similar to that in pyramidal and spinal neurons, the NMDA/AMPA ratio measured at the soma of $\mathrm{PHN}$ neurons may actually be smaller at synaptic sites presumably located at the dendrites. Despite this rough estimate, our results suggest that the expression of NMDA

A

B

C
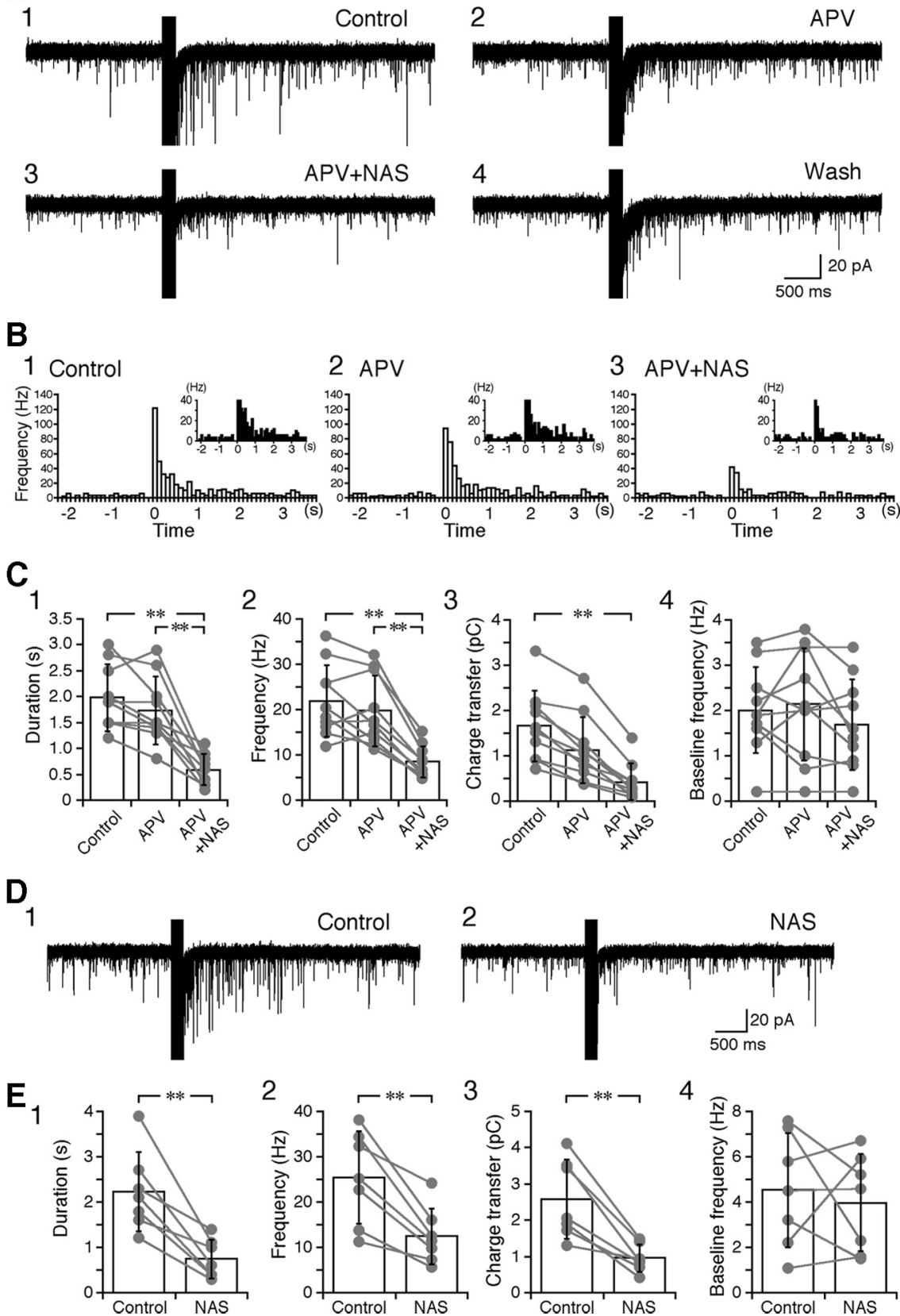

Figure 4. EPSC responses were reduced by blockade of $\mathrm{Ca}^{2+}$-permeable AMPA receptors. $A$, EPSC responses of a PHN neuron to local burst stimulation in control solution (A1), in a solution containing $50 \mu \mathrm{m} \mathrm{APV} \mathrm{(A2),} \mathrm{in} \mathrm{a} \mathrm{solution} \mathrm{containing} \mathrm{APV} \mathrm{and} 50 \mu \mathrm{m} N A S(A 3)$, and after the washing out of APV and NAS (A4). B , Histograms showing the frequency of EPSCs against time in control solution (B1), in a solution containing APV (B2), and in a solution containing APV and NAS (B3). Bin width of the histogram is $100 \mathrm{~ms}$. Inset, Histograms in which the ordinate is expanded. C, Comparisons of the duration (C1), EPSC frequency (C2), charge transfer (C3) after burst stimulation, and baseline EPSC frequency before burst stimulation (C4) in the three different recording conditions. The gray plots connected by a line were obtained from individual neurons $(n=10)$. D, EPSC responses of a PHN neuron to burst stimulation in the control solution (D1) and in a solution containing $50 \mu \mathrm{m}$ NAS (D2). E, Comparisons of the duration (E1), EPSC frequency (E2), charge transfer (E3), and baseline EPSC frequency $(\boldsymbol{E} 4)$ between the control solution and a solution containing NAS. The gray plots connected by a line were obtained from individual neurons $(n=7)$. All traces are presented as the superimposition of three traces. The asterisks indicate significant differences between groups $\left({ }^{* *} p<0.01\right.$, post hoc test in $C$. Error bars represent SD.

receptors is higher in $\mathrm{PHN}$ neurons expressing CI-AMPA receptors alone than in neurons expressing CP-AMPA receptors.

Contribution of $\mathrm{Ca}^{2+}$-activated nonselective cation channels to the sustained EPSC responses

It has been shown that neural activity is prolonged by the activation of $\mathrm{Ca}^{2+}$-activated nonselective cation (CAN) channels 
A

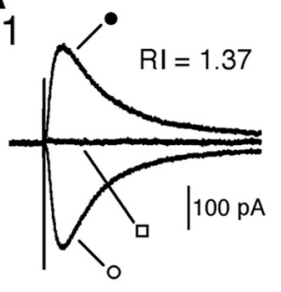

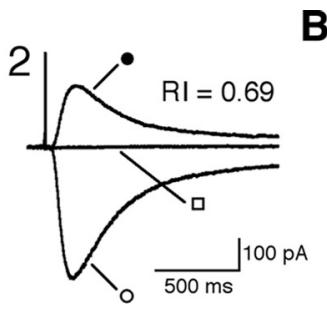

D

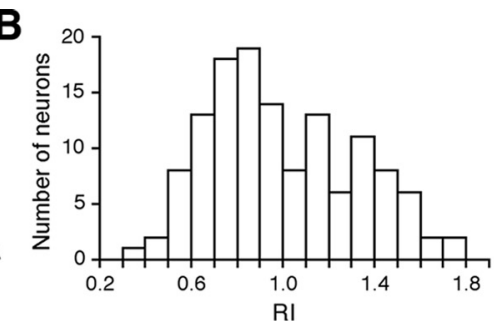

C
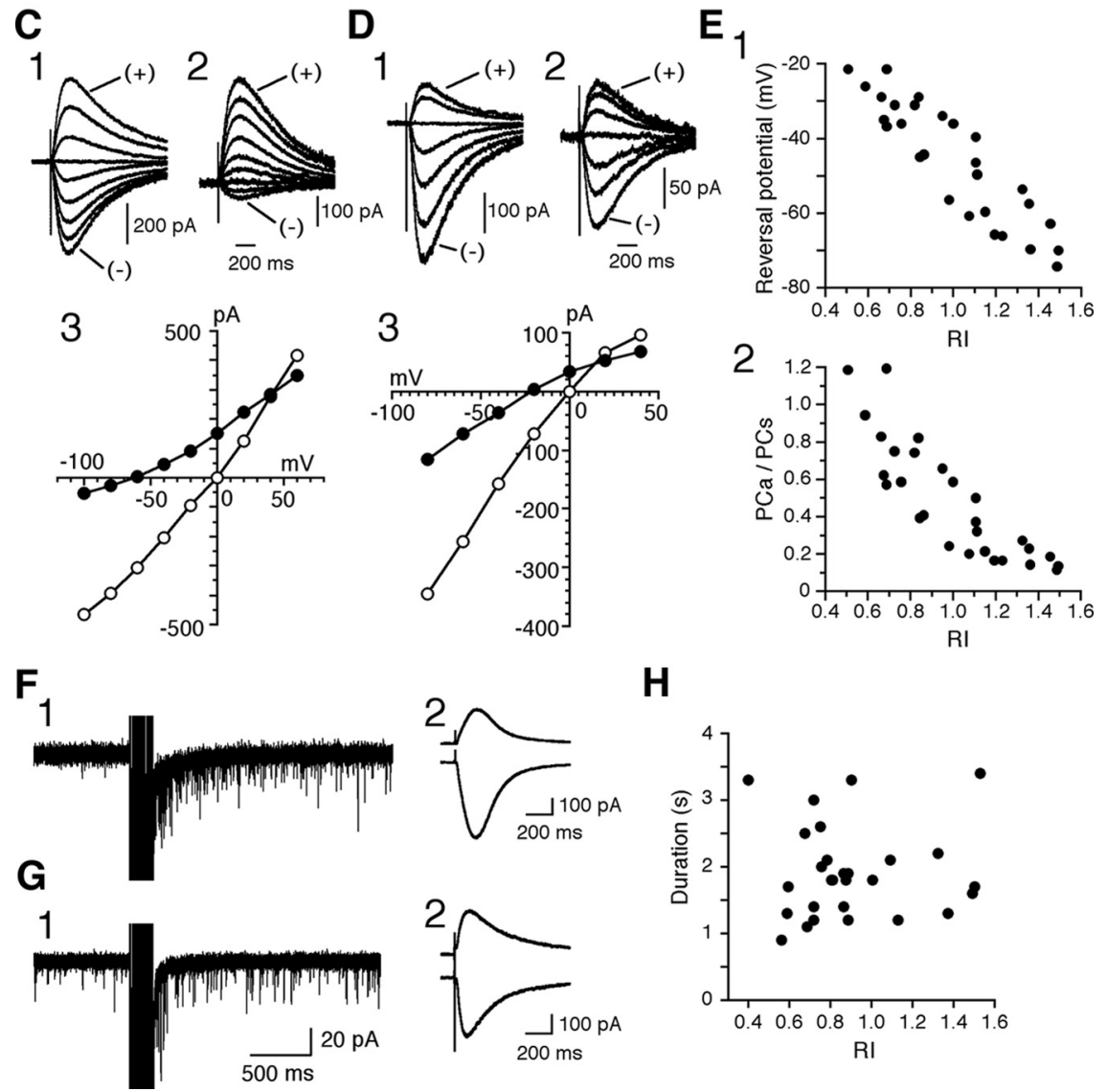

H

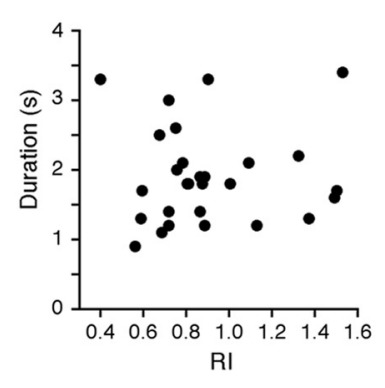

Figure 5. Characteristics of AMPA receptors in PHN neurons. $\boldsymbol{A}$, Current responses of two different PHN neurons $(\boldsymbol{A} 1, \boldsymbol{A 2})$ to an iontophoretic application of $20 \mathrm{~mm}$ kainate at a holding potential of $+40 \mathrm{mV}(\bigcirc), 0 \mathrm{mV}(\square)$, and $-60 \mathrm{mV}(\bigcirc)$. Each trace is the average of three recordings. The values of the RI are different in the two neurons as described at the right. $B, A$ histogram of PHN neurons exhibiting different RI values $(n=131)$. $\boldsymbol{C}, \boldsymbol{D}$, Current responses of two different PHN neurons to the iontophoretic application of kainate at different holding potentials in the control solution $(\mathbf{C 1}, \mathbf{D} \mathbf{1})$ and in the $\mathrm{Na}^{+}{ }^{+}$free, high-Ca ${ }^{2+}$ solution $(\mathbf{C}$, D2). The symbols $(+)$ and $(-)$ represent current traces at a holding potential of +60 and $-100 \mathrm{mV}$ in $C$ and +40 and $-80 \mathrm{mV}$ in $D$, respectively. $\mathbf{C}, D 3$, The current-voltage $(I-V)$ relationship in the control solution (open symbols) and in a $\mathrm{Na}^{+}$-free, high-Ca ${ }^{2+}$ solution (closed symbols). $\boldsymbol{E}$, Plots of the reversal potentials obtained in a $\mathrm{Na}^{+}$-free, high-Ca ${ }^{2+}$ solution $(\boldsymbol{E} 1)$ and the relative permeability coefficients of $\mathrm{Ca}^{2+}$ to $\mathrm{Cs}^{+}$estimated from the reversal potential (E2) against the RI value obtained in the control solution $(n=28)$. The reversal potential was estimated as the potential of the intersection between the $x$-axis and the line connecting the two plots that transited from the inward to the outward current. $\boldsymbol{F}$, $\mathbf{G}$, Current responses of two different PHN neurons to local burst stimulation $(\boldsymbol{F 1}, \mathbf{G 1})$ and the iontophoretic application of $20 \mathrm{~mm}$ kainate at a holding potential of $+40 \mathrm{mV}$ (top trace) and $-60 \mathrm{mV}$ (bottom trace) $(\boldsymbol{F} \mathbf{2}, \mathbf{G 2})$. The traces are presented as the superimposition of three traces $(\boldsymbol{F 1}, \mathbf{G 1})$ and averages of three recordings $(\boldsymbol{F} \mathbf{2}, \mathbf{G} 2)$. $\boldsymbol{H}$, Relationship between the duration of increased EPSC frequency and the RI $(n=28)$.

(Morisset and Nagy, 1999; Di Prisco et al., 2000; Fransén et al., 2006), which are activated by an increase in intracellular $\mathrm{Ca}^{2+}$ concentration and generate long-lasting plateau depolarizations. Since both CP-AMPA and NMDA receptors induce $\mathrm{Ca}^{2+}$ entry, CAN channels, if expressed in PHN neurons, may be activated by an intracellular $\mathrm{Ca}^{2+}$ increase through these receptors and affect neural activity in the PHN. We investigated whether CAN channels are involved in the sustained EPSC responses to burst stimulation. When FFA $(200 \mu \mathrm{M})$, a blocker of CAN channels
RI

(Partridge and Valenzuela, 2000), was applied, the sustained EPSC responses decreased markedly (Fig. 7A). Similar to NAS application, the duration (0.7 \pm $0.4 \mathrm{~s})$, EPSC frequency $(11.3 \pm 7.6 \mathrm{~Hz})$, and charge transfer $(1.9 \pm 2.3 \mathrm{pC})$ in the presence of FFA were significantly smaller than in controls (duration: $1.6 \pm 0.7 \mathrm{~s}$, $p<0.01$; frequency: $23.6 \pm 6.8 \mathrm{~Hz}, p<$ 0.01 ; charge: $3.3 \pm 3.0 \mathrm{pC}, p<0.01 ; n=$ 9) (Fig. $7 B 1-B 3$ ), although the baseline EPSC frequency was decreased by FFA $(p<0.05)$ (Fig. 7B4). These results indicate that CAN channels are also involved in the sustained EPSC responses to burst stimulation. FFA likely reduced the sustained EPSC responses that were elicited presumably by the activation of $\mathrm{CP}$ AMPA receptors because the residual currents after the blockade of NMDA receptors by APV were also reduced by FFA (Fig. 7C). The duration (0.7 $\pm 0.5 \mathrm{~s})$, EPSC frequency $(5.8 \pm 3.8 \mathrm{~Hz})$, and charge transfer $(0.3 \pm 0.2 \mathrm{pC})$ in the presence of APV and FFA were significantly smaller than in the presence of APV alone (duration: $2.3 \pm 1.4 \mathrm{~s}, p<0.01$; frequency: $19.1 \pm 9.2 \mathrm{~Hz}, p<0.01$; charge: $2.0 \pm$ $1.5 \mathrm{pC}, p<0.05$; $n=8$ ) (Fig. 7D). This result suggests that the activation of CAN channels is involved in the activation of CP-AMPA receptors. To further clarify the relationship between CP-AMPA receptors and CAN channels, we investigated the blocking effects of NAS and FFA on EPSC responses. We first investigated the effect of FFA after NAS application. EPSC responses in the presence of both NAS and FFA were not different from the responses obtained in the presence of NAS alone (Fig. $8 \mathrm{~A}$ ). When the duration of the increased EPSC frequency, EPSC frequency, and charge transfer were compared between NAS alone and NAS plus FFA (Fig. $8 B$ ), the values were not significantly different between NAS (duration, $0.9 \pm 0.3 \mathrm{~s}$; frequency, $15.6 \pm 5.8 \mathrm{~Hz}$; charge, $0.77 \pm 0.14 \mathrm{pC} ; n=8)$ and NAS plus FFA (duration, $0.9 \pm 0.3 \mathrm{~s}, p=0.74$; frequency, $12.0 \pm 3.7 \mathrm{~Hz}, p=0.13$; charge, $0.65 \pm 0.25 \mathrm{pC}, p=0.15)$. This finding supports the idea that the activation of CAN channels is linked to the activation of CP-AMPA receptors. We next investigated the effect of NAS after FFA application (Fig. 8C). The duration in the presence of FFA and NAS $(1.0 \pm 0.5 \mathrm{~s})$ was not significantly different from the presence of FFA alone $(0.7 \pm 0.4 \mathrm{~s}$; $p=0.08 ; n=8$ ) (Fig. 8D1). However, EPSC frequency and charge transfer in the presence of FFA and NAS (frequency, $10.1 \pm 6.8 \mathrm{~Hz}$; charge, $0.63 \pm 0.42 \mathrm{pC} ; n=8$ ) were significantly smaller than in the presence of FFA alone (frequency, $16.6 \pm 6.9$ $\mathrm{Hz}, p<0.01$; charge, $1.1 \pm 0.43 \mathrm{pC}, p<0.01$ ) (Fig. 8 D2,D3). This finding raises the possibility that conductances other than CAN 
channels are also activated after the activation of CP-AMPA receptors and may contribute to the sustained EPSC responses.

\section{Discussion}

Since we aimed to investigate the synaptic transmissions in excitatory networks, all experiments were performed in the presence of strychnine and picrotoxin. In our preliminary study, current responses similar to the sustained EPSC responses to local burst stimulation were observed without strychnine and picrotoxin, although they were observed infrequently. Therefore, the sustained responses may be induced under conditions without the blockade of inhibitory transmissions, but the exposure of excitatory transmissions can help to detect the activity in excitatory networks more frequently.

In the present study, we found that PHN neurons exhibited an increase in the EPSC frequency in response to burst stimulation that was applied to the Pc or to the PHN locally. This higher EPSC frequency than the baseline lasted for several seconds and far outlasted burst stimulation. Therefore, the sustained EPSC responses induced by transient burst stimulation implies a signal conversion of transient inputs into sustained outputs. The $\mathrm{PHN}$ receives excitatory inputs from excitatory burst neurons in the ipsilateral PPRF (Igusa et al., 1980; Strassman et al., 1986). A previous study in the monkey demonstrated that PPRF burst neurons fire before and during fast eye movements at a frequency $>100 \mathrm{~Hz}$ depending on the amplitude of eye movement (Keller, 1974). Although the firing characteristics of PPRF burst neurons are not clarified in the rat, a stimulation frequency of $100 \mathrm{~Hz}$ used in the present study is likely to be in the range of the firing frequency of PPRF burst neurons.

The pharmacological blockade of CPAMPA receptors with specific blockers, such as NAS and PhTx, reduced the duration of increased EPSC responses, as well as EPSC frequency and charge transfer, after burst stimulation. This suggests that the activation of CP-AMPA receptors is necessary for the sustained EPSC responses. However, the reduction in sustained EPSC responses might be simply attributable to a decrease in the detection of EPSCs that became smaller than the threshold of EPSC detection by the blockers. If so, the baseline EPSC frequency before burst stimulation is also reduced by the blocker; however, the baseline frequency in the presence of the blockers was not statistically different from the baseline frequency in the control. Therefore, the possibility of the decrease in the EPSC detection was ruled out. 0.01). Error bars represent SD.
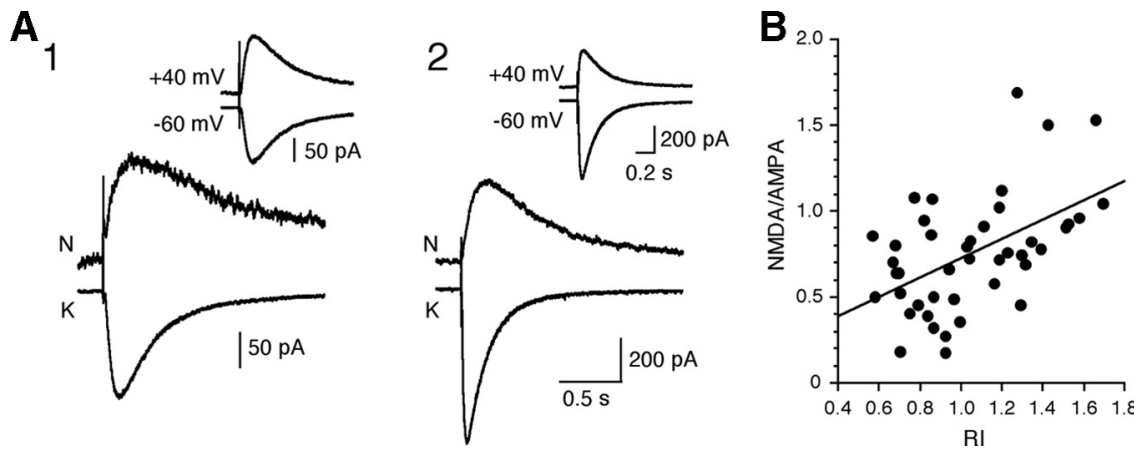

Figure 6. Relationship between the NMDA/AMPA ratio and the RI. $\boldsymbol{A}$, Current responses of two different PHN neurons $(\boldsymbol{A 1}, \boldsymbol{A 2})$ to the iontophoretic application of $20 \mathrm{~mm}$ kainate at a holding potential of $-70 \mathrm{mV}(\mathrm{K})$ and $100 \mathrm{~mm}$ NMDA at a holding potential of $+40 \mathrm{mV}(\mathrm{N})$. Insets, Current responses of the PHN neurons to the iontophoretic application of kainate at a holding potential of +40 and $-60 \mathrm{mV}$. Each trace is the average of three recordings. $B$, Relationship between the NMDA/AMPA ratio and the RI $(n=$ 43). A linear fit to the plots is superimposed.
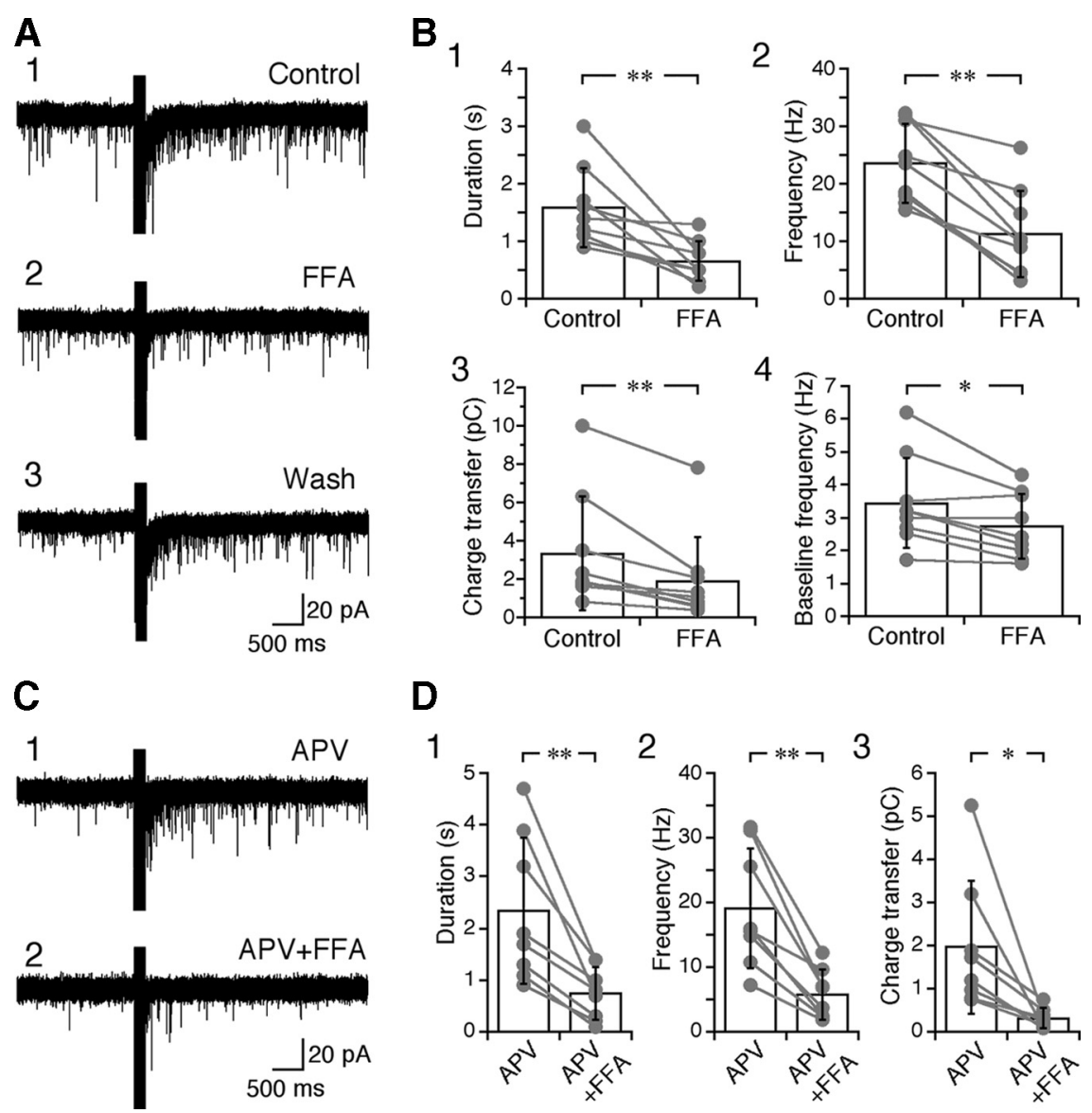

Figure 7. EPSC responses were reduced by the blockade of $\mathrm{Ca}^{2+}$-activated nonselective cation channels. $\boldsymbol{A}$, EPSC responses of a PHN neuron to local burst stimulation in the control solution (A1), in a solution containing $200 \mu \mathrm{MFF}(\boldsymbol{A 2})$, and after the washing out of FFA (A3). $\boldsymbol{B}$, Comparisons of the duration (B1), EPSC frequency (B2), charge transfer (B3), and baseline EPSC frequency $(\boldsymbol{B} 4)$ between the control solution and a solution containing FFA $(n=9)$. $\boldsymbol{C}$, EPSC responses of a PHN neuron to local burst stimulation in a solution containing $50 \mu \mathrm{m} \mathrm{APV} \mathrm{(C1)} \mathrm{and} \mathrm{in} \mathrm{a} \mathrm{solution} \mathrm{containing} \mathrm{APV} \mathrm{and} 200 \mu \mathrm{M} F F A(C 2)$. D, Comparisons of the duration (D1), EPSC frequency (D2), and charge transfer (D3) between APV alone and AVP and FFA ( $n=8)$. All traces are presented as the superimposition of three traces. The asterisks indicate significant differences between groups $\left({ }^{*} p<0.05\right.$; ${ }^{* *} p<$

Based on the results of the pharmacological analyses, a possible synaptic mechanism for the activation of neural networks in the PHN is proposed. When some PHN neurons receive burst inputs from the premotor areas, local excitatory networks in the PHN are activated. In some PHN neurons participating in the 
A

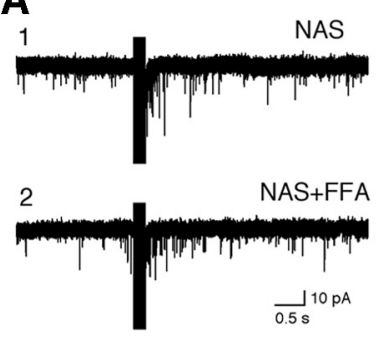

B
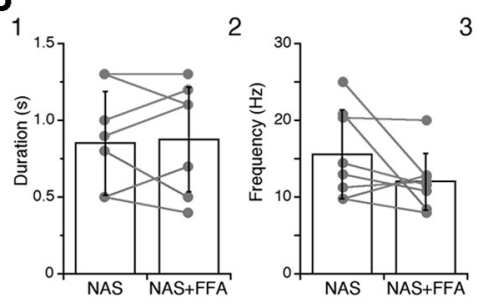

3
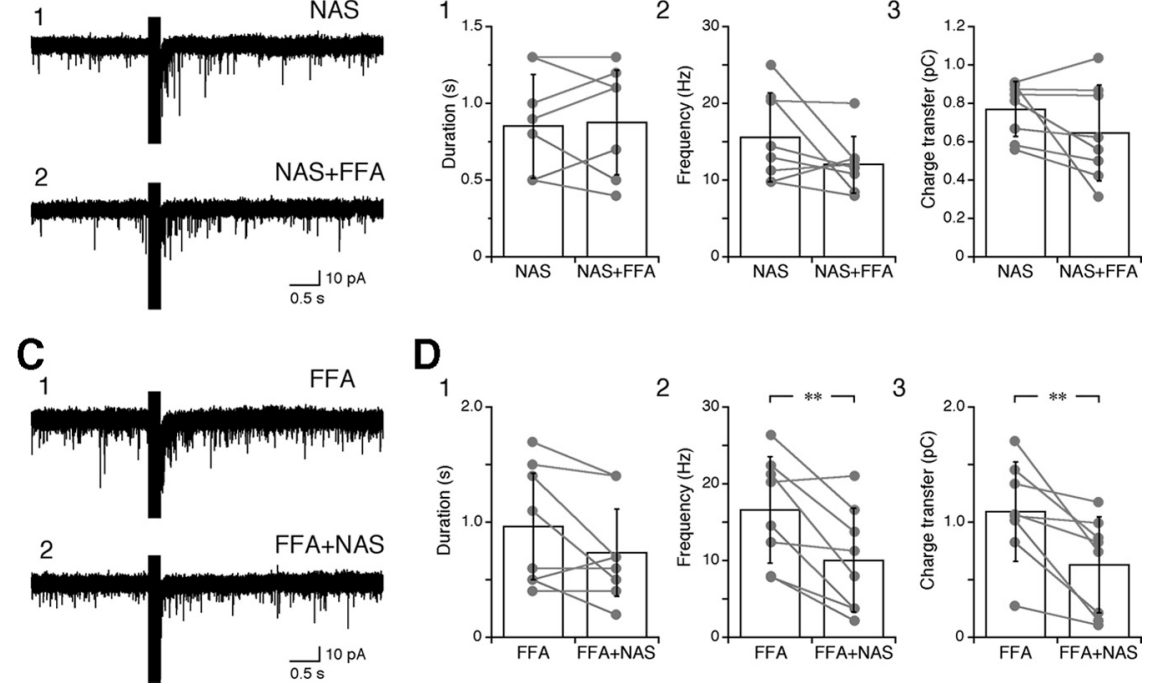

$D_{1}$
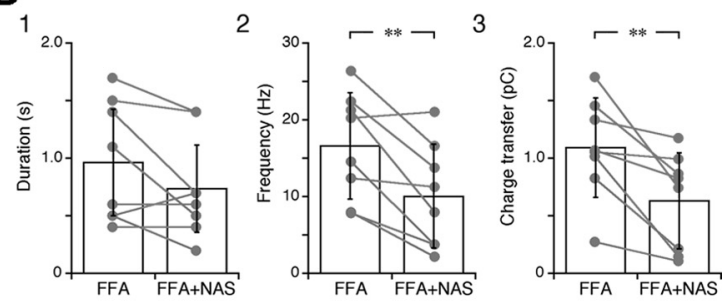

Figure 8. Effects of NAS and FFA on EPSC responses. $A$, EPSC responses of a PHN neuron to local burst stimulation in a solution containing $50 \mu \mathrm{M}$ NAS (A1) and in a solution containing NAS and $200 \mu \mathrm{M}$ FFA (A2). B, Comparisons of the duration (B1), EPSC frequency (B2), and charge transfer $(\boldsymbol{B} 3)$ between a solution containing NAS and a solution containing NAS and FFA $(n=8)$. $\boldsymbol{C}$, EPSC responses of a PHN neuron to local burst stimulation in a solution containing FFA (C1) and in a solution containing FFA and NAS (C2). D , Comparisons of the duration (D1), EPSC frequency (D2), and charge transfer (D3) between a solution containing FFA and in a solution containing FFA and NAS $(n=8)$. All traces are presented as the superimposition of three traces. The asterisks indicate significant differences between groups $\left({ }^{* *} p<0.01\right)$. Error bars represent SD.

networks, the activation of CP-AMPA receptors induces $\mathrm{Ca}^{2+}$ entry into the neurons, increasing the intracellular $\mathrm{Ca}^{2+}$ concentration. Subsequently, CAN channels are activated by the $\mathrm{Ca}^{2+}$ increase and maintain a depolarization of the neurons. The depolarized neurons can continuously activate PHN networks, and thus the PHN networks are activated persistently. The persistent activities generated in the networks are transmitted to the extraocular motoneurons for gaze holding.

CP-AMPA receptors are composed of GluA subunits but do not include the GluA2 subunit (Hollmann et al., 1991; Verdoorn et al., 1991; Burnashev et al., 1992). Although we have not clarified the subunit composition of CP-AMPA receptors in PHN neurons, a previous study has demonstrated that CP-AMPA receptors are composed of GluA1 and/or GluA4 subunits in cultured hippocampal neurons (Bochet et al., 1994). AMPA receptors without GluA2 subunits exhibit an inwardly rectifying $I-V$ relationship of synaptic responses, which is attributed to a blockade by polyamines at the positive potential (Bowie and Mayer, 1995; Donevan and Rogawski, 1995; Isa et al., 1995; Kamboj et al., 1995; Koh et al., 1995). According to the RI criteria of neurons (Ozawa et al., 1991), neurons exhibiting RI $<0.25$ are referred to as type II neurons and their AMPA-mediated excitatory synapses are composed of CP-AMPA receptors. However, neurons exhibiting $0.25 \leq \mathrm{RI}<1$ are referred to as intermediatetype neurons and their synapses are composed of a mixture of CI-AMPA and CP-AMPA receptors. The RI analysis of PHN neurons revealed that all neurons exhibiting RI $<1$ corresponded to the intermediate type, whose $\mathrm{Ca}^{2+}$ permeability $\left(P_{\mathrm{Ca}} /\right.$ $P_{\mathrm{Cs}}<1.2$ ) (Fig. 5E2) was lower than that of type II neurons $\left(P_{\mathrm{Ca}} / P_{\mathrm{Cs}} \approx 2\right)$ (Ozawa et al., 1998). The fact that all PHN neurons expressing CP-AMPA receptors corresponded to the intermediate type suggests that moderate $\mathrm{Ca}^{2+}$ permeability is suitable to prevent the entry of a large amount of $\mathrm{Ca}^{2+}$ into $\mathrm{PHN}$ neurons during activation. However, the activation of AMPA receptors is short because of their rapid desensitization (Trussell et al., 1988;
Tang et al., 1991; Sun et al., 2002). Therefore, it is plausible that a slight amount of $\mathrm{Ca}^{2+}$ enters through the CP-AMPA receptors even when burst inputs from the premotor neurons activate CP-AMPA receptors repeatedly. If the slight $\mathrm{Ca}^{2+}$ entry through CP-AMPA receptors can indeed activate CAN channels, it would be expected that CAN channels have a spatially intimate relationship with CP-AMPA receptors sufficient to detect the local $\mathrm{Ca}^{2+}$ elevation. Additional investigation is required to clarify the relationship between CP-AMPA receptors and CAN channels in PHN neurons.

A novel finding in our study is that CP-AMPA receptors contribute to the sustained EPSC responses observed. This sustained activity is observed not only in oculomotor system but also in various brain regions, including the cerebral cortex and hippocampus (Wang, 2001; Major and Tank, 2004), in which CP-AMPA receptors are mainly expressed on inhibitory interneurons (Liu and Zukin, 2007). Although we further propose that the activation of $\mathrm{CAN}$ channels by $\mathrm{Ca}^{2+}$ entry through CP-AMPA receptors is one of the important pathways for the induction of the sustained activity, CAN channels are also activated by $\mathrm{Ca}^{2+}$ entry through NMDA receptors (Di Prisco et al., 2000; Hall and Delaney, 2002; Zhu et al., 2004). Given the finding that the excitatory synaptic responses in PHN neurons evoked by the stimulation of the PPRF were completely abolished by CNQX (Navarro-López et al., 2004), a CP-AMPA receptor-dependent sustained activity may be unique to $\mathrm{PHN}$ circuits.

Previous studies suggest that, if the recurrent excitatory network is driven only by fast synaptic transmissions mediated by AMPA receptors, the sustained activity generated by the network cannot be robust (Seung et al., 2000; Wang, 2001). For keeping the robust activity, the recurrent network is needed to add some slower responses derived from synaptic or dendritic properties. Since NMDA receptor-mediated currents show slow kinetics, it has been suggested that NMDA receptors contribute to the neural integrator and the integrator network is composed of synaptic transmissions with a higher NMDA/AMPA ratio (Wang, 1999; Compte et al., 2000; Tegnér et al., 2002). In the present study, the iontophoretic application of NMDA induced current responses in all PHN neurons tested (Fig. 6). PHN neurons expressing CIAMPA receptors alone, which showed higher NMDA/AMPA ratios than those expressing CP-AMPA receptors, also showed the sustained EPSC responses to the burst stimulation (Fig. $5 \mathrm{~F}-\mathrm{H}$ ), suggesting the contribution of NMDA receptors to the EPSC responses. However, we did not find a substantial effect of APV on the sustained EPSC responses. These findings suggest that, in PHN neurons expressing CI-AMPA receptors alone, the amount of NMDA receptors at synaptic sites is insufficient to affect PHN networks, or the PHN neurons do not participate in the primary networks for the generation and maintenance of the sustained EPSC responses.

The findings of the sustained EPSC responses raise a question of how much impact changes in synaptic events actually have on the persistent firings of PHN neurons. In our prelim- 
inary current-clamp study, a majority of PHN neurons tested showed that the duration of the increased frequency of spontaneous firings was much shorter than the duration of the increased EPSC frequency (supplemental Fig. S3, available at www.jneurosci.org as supplemental material). This finding indicates that the synaptic events induced in this study have little impact on the sustained increase in firing frequency. Although this small impact may be attributable to the difficulty in the induction of high synaptic events sufficient to cause a change in firings in slice preparations, additional investigations performed under different stimulus conditions are needed to clarify the synaptic effect on firings.

The finding that the sustained EPSC responses occurred in the isolated PHN suggests that the excitatory networks necessary for gaze holding exist within the PHN. It has been reported that the time constant of a centripetal drift after an eye movement to an eccentric direction (i.e., the time constant for the neural integrator) is $>20 \mathrm{~s}$ in the cat (Robinson, 1974), monkey (Cannon and Robinson, 1987), and human (Becker and Klein, 1973). Although the time constant in the rodent $(\approx 2 \mathrm{~s})$ [rat (Chelazzi et al., 1989); mouse (van Alphen et al., 2001)] is shorter than that in the cat and primates, it is longer than the duration of the EPSC responses observed in the present study. Therefore, the local PHN network alone is unlikely to be sufficient to explain the mechanism of gaze holding. Although the lack of long persistence in this study could simply be attributable to damage to the network connectivity in slice preparations, previous studies suggest that (1) functional interactions with the vestibular nuclei, (2) positive feedback excitations via the cerebellar circuits, and (3) modulatory effects by cholinergic inputs, play significant roles in the functions of the neural integrator (Fukushima et al., 1992; Fukushima and Kaneko, 1995; Delgado-García et al., 2006). By combining all of these factors, neural activity may be sustained long enough for gaze holding.

\section{References}

Aksay E, Gamkrelidze G, Seung HS, Baker R, Tank DW (2001) In vivo intracellular recording and perturbation of persistent activity in a neural integrator. Nat Neurosci 4:184-193.

Aksay E, Baker R, Seung HS, Tank DW (2003) Correlated discharge among cell pairs within the oculomotor horizontal velocity-to-position integrator. J Neurosci 23:10852-10858.

Andrasfalvy BK, Magee JC (2001) Distance-dependent increase in AMPA receptor number in the dendrites of adult hippocampal CA1 pyramidal neurons. J Neurosci 21:9151-9159.

Anwyl R (1999) Metabotropic glutamate receptors: electrophysiological properties and role in plasticity. Brain Res Brain Res Rev 29:83-120.

Arnold DB, Robinson DA (1997) The oculomotor integrator: testing of a neural network model. Exp Brain Res 113:57-74.

Arnold DB, Robinson DA, Leigh RJ (1999) Nystagmus induced by pharmacological inactivation of the brainstem ocular motor integrator in monkey. Vis Res 39:4286-4295.

Asami T, Kagechika H, Hashimoto Y, Shudo K, Miwa A, Kawai N, Nakajima $\mathrm{T}$ (1989) Acylpolyamines mimic the action of joro spider toxin (JSTX) on crustacean muscle glutamate receptors. Biomed Res 10:185-189.

Becker W, Klein HM (1973) Accuracy of saccadic eye movements and maintenance of eccentric eye positions in the dark. Vision Res 13:1021-1034.

Blaschke M, Keller BU, Rivosecchi R, Hollmann M, Heinemann S, Konnerth A (1993) A single amino acid determines the subunit-specific spider toxin block of alpha-amino-3-hydroxy-5-methylisoxazole-4propionate/kainate receptor channels. Proc Natl Acad Sci U S A 90:6528-6532

Bochet P, Audinat E, Lambolez B, Crépel F, Rossier J, Iino M, Tsuzuki K, Ozawa S (1994) Subunit composition at the single-cell level explains functional properties of a glutamate-gated channel. Neuron 12:383-388.

Bowie D, Mayer ML (1995) Inward rectification of both AMPA and kainate subtype glutamate receptors generated by polyamine-mediated ion channel block. Neuron 15:453-462.

Burnashev N, Monyer H, Seeburg PH, Sakmann B (1992) Divalent ion permeability of AMPA receptor channels is dominated by the edited form of a single subunit. Neuron 8:189-198.

Cannon SC, Robinson DA (1985) An improved neural-network model for the neural integrator of the oculomotor system: more realistic neuron behavior. Biol Cybern 53:93-108.

Cannon SC, Robinson DA (1987) Loss of the neural integrator of the oculomotor system from brain stem lesions in monkey. J Neurophysiol 57:1383-1409.

Cannon SC, Robinson DA, Shamma S (1983) A proposed neural network for the integrator of the oculomotor system. Biol Cybern 49:127-136.

Chelazzi L, Rossi F, Tempia F, Ghirardi M, Strata P (1989) Saccadic eye movements and gaze holding in the head-restrained pigmented rat. Eur J Neurosci 1:639-646.

Cheron G, Godaux E (1987) Disabling of the oculomotor neural integrator by kainic acid injections in the prepositus-vestibular complex of the cat J Physiol 394:267-290.

Cheron G, Godaux E, Laune JM, Vanderkelen B (1986a) Lesions in the cat prepositus complex: effects on the vestibulo-ocular reflex and saccades. J Physiol 372:75-94.

Cheron G, Gillis P, Godaux E (1986b) Lesions in the cat prepositus complex: effects on the optokinetic system. J Physiol 372:95-111.

Cheron G, Mettens P, Godaux E (1992) Gaze holding defect induced by injections of ketamine in the cat brainstem. Neuroreport 3:97-100.

Compte A, Brunel N, Goldman-Rakic PS, Wang XJ (2000) Synaptic mechanisms and network dynamics underlying spatial working memory in a cortical network model. Cereb Cortex 10:910-923.

Delgado-García JM, Vidal PP, Gómez C, Berthoz A (1989) A neurophysiological study of prepositus hypoglossi neurons projecting to oculomotor and preoculomotor nuclei in the alert cat. Neuroscience 29:291-307.

Delgado-García JM, Yajeya J, Navarro-López Jde D (2006) A cholinergic mechanism underlies persistent neural activity necessary for eye fixation. Prog Brain Res 154:211-224.

Di Prisco GV, Pearlstein E, Le Ray D, Robitaille R, Dubuc R (2000) A cellular mechanism for the transformation of a sensory input into a motor command. J Neurosci 20:8169-8176.

Dodt HU, Frick A, Kampe K, Zieglgänsberger W (1998) NMDA and AMPA receptors on neocortical neurons are differentially distributed. Eur J Neurosci 10:3351-3357.

Donevan SD, Rogawski MA (1995) Intracellular polyamines mediate inward rectification of $\mathrm{Ca}^{2+}$-permeable alpha-amino-3-hydroxy-5methyl-4-isoxazolepropionic acid receptors. Proc Natl Acad Sci U S A 92:9298-9302.

Draye JP, Cheron G, Libert G, Godaux E (1997) Emergence of clusters in the hidden layer of a dynamic recurrent neural network. Biol Cybern 76:365-374.

Eldefrawi AT, Eldefrawi ME, Konno K, Mansour NA, Nakanishi K, Oltz E, Usherwood PN (1988) Structure and synthesis of a potent glutamate receptor antagonist in wasp venom. Proc Natl Acad Sci U S A 85:4910-4913.

Escudero M, de la Cruz RR, Delgado-García JM (1992) A physiological study of vestibular and prepositus hypoglossi neurones projecting to the abducens nucleus in the alert cat. J Physiol 458:539-560.

Fransén E, Tahvildari B, Egorov AV, Hasselmo ME, Alonso AA (2006) Mechanism of graded persistent cellular activity of entorhinal cortex layer V neurons. Neuron 49:735-746.

Fuchs AF, Luschei ES (1970) Firing patterns of abducens neurons of alert monkeys in relationship to horizontal eye movement. J Neurophysiol 33:382-392.

Fukushima K, Kaneko CR (1995) Vestibular integrators in the oculomotor system. Neurosci Res 22:249-258.

Fukushima K, Kaneko CR, Fuchs AF (1992) The neuronal substrate of integration in the oculomotor system. Prog Neurobiol 39:609-639.

Galiana HL, Outerbridge JS (1984) A bilateral model for central neural pathways in vestibuloocular reflex. J Neurophysiol 51:210-241.

Goldman-Rakic PS (1995) Cellular basis of working memory. Neuron 14:477-485.

Hall BJ, Delaney KR (2002) Contribution of a calcium-activated nonspecific conductance to NMDA receptor-mediated synaptic potentials in granule cells of the frog olfactory bulb. J Physiol 543:819-834. 
Hollmann M, Hartley M, Heinemann S (1991) $\mathrm{Ca}^{2+}$ permeability of KAAMPA-gated glutamate receptor channels depends on subunit composition. Science 252:851-853.

Hölscher C, Gigg J, O’Mara SM (1999) Metabotropic glutamate receptor activation and blockade: their role in long-term potentiation, learning and neurotoxicity. Neurosci Biobehav Rev 23:399-410.

Hume RI, Dingledine R, Heinemann SF (1991) Identification of a site in glutamate receptor subunits that controls calcium permeability. Science 253:1028-1031.

Idoux E, Serafin M, Fort P, Vidal PP, Beraneck M, Vibert N, Mühlethaler M, Moore LE (2006) Oscillatory and intrinsic membrane properties of guinea pig nucleus prepositus hypoglossi neurons in vitro. J Neurophysiol 96:175-196.

Igusa Y, Sasaki S, Shimazu H (1980) Excitatory premotor burst neurons in the cat pontine reticular formation related to the quick phase of vestibular nystagmus. Brain Res 182:451-456.

Iino M, Ozawa S, Tsuzuki K (1990) Permeation of calcium through excitatory amino acid receptor channels in cultured rat hippocampal neurones. J Physiol 424:151-165.

Isa T, Iino M, Itazawa S, Ozawa S (1995) Spermine mediates inward rectification of $\mathrm{Ca}^{2+}$-permeable AMPA receptor channels. Neuroreport 6:2045-2048.

Iwasaki H, Kani K, Maeda T (1999) Neural connections of the pontine reticular formation, which connects reciprocally with the nucleus prepositus hypoglossi in the rat. Neuroscience 93:195-208.

Jonas P, Burnashev N (1995) Molecular mechanisms controlling calcium entry through AMPA-type glutamate receptor channels. Neuron 15:987-990.

Kamboj SK, Swanson GT, Cull-Candy SG (1995) Intracellular spermine confers rectification on rat calcium-permeable AMPA and kainate receptors. J Physiol 486:297-303.

Kawai N, Niwa A, Abe T (1982) Spider venom contains specific receptor blocker of glutaminergic synapses. Brain Res 247:169-171.

Keller EL (1974) Participation of medial pontine reticular formation in eye movement generation in monkey. J Neurophyiol 37:316-332.

Kiehn O, Eken T (1998) Functional role of plateau potentials in vertebrate motor neurons. Curr Opin Neurobiol 8:746-752.

Kiskin NI, Krishtal OA, Tsyndrenko AYa (1986) Excitatory amino acid receptors in hippocampal neurons: kainate fails to desensitize them. Neurosci Lett 63:225-230.

Koh DS, Burnashev N, Jonas P (1995) Block of native $\mathrm{Ca}^{2+}$-permeable AMPA receptors in rat brain by intracellular polyamines generates double rectification. J Physiol 486:305-312.

Koike M, Iino M, Ozawa S (1997) Blocking effect of 1-naphthyl acetyl spermine on $\mathrm{Ca}^{2+}$-permeable AMPA receptors in cultured rat hippocampal neurons. Neurosci Res 29:27-36.

Liu SJ, Zukin RS (2007) $\mathrm{Ca}^{2+}$-permeable AMPA receptors in synaptic plasticity and neuronal death. Trends Neurosci 30:126-134.

Lopez-Barneo J, Darlot C, Berthoz A, Baker R (1982) Neuronal activity in prepositus nucleus correlated with eye movement in the alert cat. J Neurophysiol 47:329-352.

Major G, Tank D (2004) Persistent neural activity: prevalence and mechanisms. Curr Opin Neurobiol 14:675-684.

McCrea RA (1988) Neuroanatomy of the oculomotor system. The nucleus prepositus. Rev Oculomot Res 2:203-223.

McCrea RA, Baker R (1985a) Cytology and intrinsic organization of the perihypoglossal nuclei in the cat. J Comp Neurol 237:360-376.

McCrea RA, Baker R (1985b) Anatomical connections of the nucleus prepositus of the cat. J Comp Neurol 237:377-407.

McCrea RA, Horn AK (2006) Nucleus prepositus. Prog Brain Res 151:205-230.

McFarland JL, Fuchs AF (1992) Discharge patterns in nucleus prepositus hypoglossi and adjacent medial vestibular nucleus during horizontal eye movement in behaving macaques. J Neurophysiol 68:319-332.

Mettens P, Cheron G, Godaux E (1994a) NMDA receptors are involved in temporal integration in the oculomotor system of the cat. Neuroreport 5:1333-1336.

Mettens P, Godaux E, Cheron G, Galiana HL (1994b) Effect of muscimol microinjections into the prepositus hypoglossi and medial vestibular nuclei on cat eye movements. J Neurophysiol 72:785-802.

Morisset V, Nagy F (1999) Ionic basis for plateau potentials in deep dorsal horn neurons of the rat spinal cord. J Neurosci 19:7309-7316.
Moschovakis AK (1997) The neural integrators of the mammalian saccadic system. Front Biosci 2:d552-d577.

Navarro-López Jde D, Alvarado JC, Márquez-Ruiz J, Escudero M, DelgadoGarcía JM, Yajeya J (2004) A cholinergic synaptically triggered event participates in the generation of persistent activity necessary for eye fixation. J Neurosci 24:5109-5118.

Navarro-López Jde D, Delgado-García JM, Yajeya J (2005) Cooperative glutamatergic and cholinergic mechanisms generate short-term modifications of synaptic effectiveness in prepositus hypoglossi neurons. J Neurosci 25:9902-9906.

Ohishi H, Shigemoto R, Nakanishi S, Mizuno N (1993a) Distribution of the messenger RNA for a metabotropic glutamate receptor, mGluR2, in the central nervous system of the rat. Neuroscience 53:1009-1018.

Ohishi H, Shigemoto R, Nakanishi S, Mizuno N (1993b) Distribution of the mRNA for a metabotropic glutamate receptor (mGluR3) in the rat brain: an in situ hybridization study. J Comp Neurol 335:252-266.

Onodera K, Takeuchi A (1991) Uneven distribution of excitatory amino acid receptors on ventral horn neurones of newborn rat spinal cord. J Physiol 439:257-276.

Ozawa S, Iino M (1993) Two distinct types of AMPA responses in cultured rat hippocampal neurons. Neurosci Lett 155:187-190.

Ozawa S, Iino M, Tsuzuki K (1991) Two types of kainate response in cultured rat hippocampal neurons. J Neurophysiol 66:2-11.

Ozawa S, Kamiya H, Tsuzuki K (1998) Glutamate receptors in the mammalian central nervous system. Prog Neurobiol 54:581-618.

Partridge LD, Valenzuela CF (2000) Block of hippocampal CAN channels by flufenamate. Brain Res 867:143-148.

Patneau DK, Mayer ML (1991) Kinetic analysis of interactions between kainate and AMPA: evidence for activation of a single receptor in mouse hippocampal neurons. Neuron 6:785-798.

Paxinos G, Watson C (2007) The rat brain in stereotaxic coordinates, Ed 6. Burlington, MA: Academic.

Plant K, Pelkey KA, Bortolotto ZA, Morita D, Terashima A, McBain CJ, Collingridge GL, Isaac JT (2006) Transient incorporation of native GluR2-lacking AMPA receptors during hippocampal long-term potentiation. Nat Neurosci 9:602-604.

Robinson DA (1970) Oculomotor unit behavior in the monkey. J Neurophysiol 33:393-403.

Robinson DA (1974) The effect of cerebellectomy on the cat's vestibuloocular integrator. Brain Res 71:195-207.

Robinson DA (1975) Oculomotor control signals. In: Basic mechanisms of ocular motility and their clinical implications (Lennerstrand G, Bach-yRita P, eds), pp 337-374. Oxford: Pergamon.

Robinson DA (1989) Integrating with neurons. Annu Rev Neurosci 12:33-45.

Satake S, Song SY, Cao Q, Satoh H, Rusakov DA, Yanagawa Y, Ling EA, Imoto K, Konishi S (2006) Characterization of AMPA receptors targeted by the climbing fiber transmitter mediating presynaptic inhibition of GABAergic transmission at cerebellar interneuron-Purkinje cell synapses. J Neurosci 26:2278-2289.

Schiller PH (1970) The discharge characteristics of single units in the oculomotor and abducens nuclei of the unanesthetized monkey. Exp Brain Res 10:347-362.

Seung HS, Lee DD, Reis BY, Tank DW (2000) Stability of the memory of eye position in a recurrent network of conductance-based model neurons. Neuron 26:259-271.

Shigemoto R, Nakanishi S, Mizuno N (1992) Distribution of the mRNA for a metabotropic glutamate receptor (mGluR1) in the central nervous system: an in situ hybridization study in adult and developing rat. J Comp Neurol 322:121-135.

Strassman A, Highstein SM, McCrea RA (1986) Anatomy and physiology of saccadic burst neurons in the alert squirrel monkey. I. Excitatory burst neurons. J Comp Neurol 249:337-357.

Sun Y, Olson R, Horning M, Armstrong N, Mayer M, Gouaux E (2002) Mechanism of glutamate receptor desensitization. Nature 417:245-253.

Tang CM, Shi QY, Katchman A, Lynch G (1991) Modulation of the time course of fast EPSCs and glutamate channel kinetics by aniracetam. Science 254:288-290.

Tegnér J, Compte A, Wang XJ (2002) The dynamical stability of reverberatory neural circuits. Biol Cybern 87:471-481. 
Tóth K, McBain CJ (1998) Afferent-specific innervation of two distinct AMPA receptor subtypes on single hippocampal interneurons. Nat Neurosci 1:572-578.

Trussell LO, Thio LL, Zorumski CF, Fischbach GD (1988) Rapid desensitization of glutamate receptors in vertebrate central neurons. Proc Natl Acad Sci U S A 85:4562-4566.

van Alphen AM, Stahl JS, De Zeeuw CI (2001) The dynamic characteristics of the mouse horizontal vestibulo-ocular and optokinetic response. Brain Res 890:296-305.

Van Gisbergen JA, Robinson DA, Gielen S (1981) A quantitative analysis of generation of saccadic eye movements by burst neurons. J Neurophysiol 45:417-442.

Verdoorn TA, Burnashev N, Monyer H, Seeburg PH, Sakmann B (1991)
Structural determinants of ion flow through recombinant glutamate receptor channels. Science 252:1715-1718.

Wang XJ (1999) Synaptic basis of cortical persistent activity: the importance of NMDA receptors to working memory. J Neurosci 19: 9587-9603.

Wang XJ (2001) Synaptic reverberation underlying mnemonic persistent activity. Trends Neurosci 24:455-463.

Washburn MS, Dingledine R (1996) Block of alpha-amino-3-hydroxy-5methyl-4-isoxazolepropionic acid (AMPA) receptors by polyamines and polyamine toxins. J Pharmacol Exp Ther 278:669-678.

Zhu ZT, Munhall A, Shen KZ, Johnson SW (2004) Calcium-dependent subthreshold oscillations determine bursting activity induced by $N$-methyl-Daspartate in rat subthalamic neurons in vitro. Eur J Neurosci 19:1296-1304. 